\title{
Challenges for Air Transport Providers in Czech Republic and Poland
}

\author{
Anna Toruń, ${ }^{1}$ Czesław Burniak, ${ }^{1}$ Jerzy Biały, ${ }^{1}$ Justyna Tomaszewska (D), ${ }^{1}$ Norbert Grzesik, \\ Sarka Hoskova-Mayerova $\left(\mathbb{D},{ }^{2}\right.$ Marta Woch, ${ }^{3}$ Mariusz Zieja, ${ }^{4}$ and Adam Rurak ${ }^{5}$ \\ ${ }^{1}$ Polish Air Force Academy, Faculty of Aviation, 08-521 Dęblin, Poland \\ ${ }^{2}$ University of Defence, Faculty of Military Technology, 66210 Brno, Czech Republic \\ ${ }^{3}$ Warsaw University of Technology, Division of Fundamentals of Machine Design, Faculty of Power and Aeronautical Engineering, \\ 00665 Warsaw, Poland \\ ${ }^{4}$ Air Force Institute of Technology, Division for IT Support of Logistics, 01-494 Warsaw, Poland \\ ${ }^{5}$ Polish Air Force Academy, Faculty of National Security and Logistics, 08-521 Dęblin, Poland
}

Correspondence should be addressed to Justyna Tomaszewska; j.tomaszewska@wsosp.pl

Received 8 June 2018; Revised 1 October 2018; Accepted 4 October 2018; Published 1 November 2018

Guest Editor: Ondrej Stopka

Copyright (c) 2018 Anna Toruń et al. This is an open access article distributed under the Creative Commons Attribution License, which permits unrestricted use, distribution, and reproduction in any medium, provided the original work is properly cited.

The aim of this paper is to find a trend in air transport behaviour in the Czech Republic and Poland, based on data collected between the years of 2004 and 2016. The choice of data period for the analysis was made because of the date when both mentioned countries joined the European Union and availability of data. The data used in this article is provided from the Eurostat web page where many revealing statistics are collected. The correlations of indicators were chosen as a method of the analysis. It was observed that the number of passengers increased up to $30 \%$ and $460 \%$, respectively, in the Czech Republic and in Poland. The authors will explain possible reasons and aspects of such behaviour in order to make some predictions for future trends in air transport. The additional aim is to understand transport processes and economic growth in neighbouring countries during the period of focus. The knowledge of conditional changes in the number of passengers utilizing air transport grants the ability to make forecasts about the needed infrastructure, number of aircrafts, pilots, and staff needed at the airports.

\section{Introduction}

The increase in demand for air transport has led to specialization in a wide range of tasks. As a result of changes in the development of air transport due to the use of different tasks, it can be divided into transport aviation and general aviation [1]. Transport aviation is the transport of goods and mail in an organized manner by aircraft, i.e., airplanes, helicopters, and airships. This type of air transport is characterized by the highest transport speeds, adapted to the type of aircraft. The dominant mode of air transport is passenger transport. These may be scheduled flights, called scheduled flights, or nonscheduled flights, of which an example would be charter flights. In terms of coverage, we can distinguish between short, medium, and long-haul passenger aviation.
The attractiveness of air passenger transport is determined by the high standard of service, its speed, regularity, and safety. The statistical data confirms the safety of air services in comparison with other modes of transport.

All authors have strong mathematical and statistical background, and they would like to point out some dependencies, but they do not intend to interpret it very deeply from the economical point of view.

\section{Methodology}

There are various statistical methods and algorithms that can be used, so it is important to have a classification of the existing methods. The choice of method depends on the problem analyzed or the type of data available. The data mining process is guided by the applications. For this reason, 
the used methods can be classified according to the aim of the analysis. As a result, three main classes can be distinguished:

(i) Descriptive methods: they aim to describe groups of data more briefly; they are also called symmetrical, unsupervised, or indirect methods. Observations may be classified into groups not known beforehand (cluster analysis, Kohonen maps); variables may be connected among themselves according to links previously unknown (association methods, log-linear models, and graphical models). In this way, all the variables available are treated at the same level and there are no hypotheses of causality.

(ii) Predictive methods: they aim to describe one or more of the variables in relation to other; they are also called asymmetrical, supervised, or direct methods. This is performed by searching for rules of classification or prediction based on the data. These rules enable us to predict or classify the future result of one or more responses or target variables in relation to what happens to the explanatory or input variables. The main methods of this type are those developed in the field of machine learning such as the neural networks (multilayer perceptrons) and decision trees, but also classic statistical models such as linear and logistic regression models.

(iii) Local methods: they aim to identify particular characteristics related to subset interests of the database; descriptive methods and predictive methods are global rather than local. Examples of local methods are association rules for analyzing transactional data and the identification of anomalous observations.

The method based on the relationship between two or more variables was chosen to be the main method of the analysis. This method is usually called correlation; however in this analysis it is nonsensical correlation, an example being the correlation between a decreasing number of passengers in country A and country B. Such a correlation can be high simply because both variables are related to the state of economy [2].

To characterize this behaviour, parametric and nonparametric measures may be used to assess the relationship between the two characteristics. In this paper, a parametric measure called the Pearson coefficient has been applied, which determines the collinearity of the two features. It is described by the following formula $[3,4]$ :

$$
\begin{aligned}
& r=\frac{c_{X Y}}{S_{x} S_{y}}=\frac{\sum_{i=1}^{n}\left(x_{i}-\bar{x}\right)\left(y_{i}-\bar{y}\right)}{\sqrt{\sum_{i=1}^{n}\left(x_{i}-\bar{x}\right)^{2} \sum_{i=1}^{n}\left(y_{i}-\bar{y}\right)^{2}}} \\
& i=1,2, \ldots, n
\end{aligned}
$$

where $c_{X Y}=(1 /(n-1)) \sum_{i=1}^{n}\left(x_{i}-\bar{x}\right)\left(y_{i}-\bar{y}\right)$ is an estimator of correlation $\operatorname{cov}(\mathrm{X}, \mathrm{Y}) ; S_{x}, S_{y}$ are estimators of standard deviation. If $\rho$-a population correlation-is zero, then the probability for a given sample correlation-its statistical significance-depends on the sample size [5]. Therefore, we combine the sample size and $\mathrm{r}$ into a single number, our test statistic t:

$$
T=R \sqrt{\frac{n-2}{1-R^{2}}}
$$

Now, $T$ itself is not interesting. However, it is needed to find significant levels for some dependencies. $T$ follows a $t$ distribution with $n$-2 degrees of freedom [6]. The strength of the relationship varies in degree based on the value of the correlation coefficient [7].

2.1. Data Sample. The data used in this analysis is taken from the Eurostat web page [8]. The Eurostat web page is provided free of charge via Internet and its statistical databases are accessible via the Internet. The statistics are hierarchically ordered in a navigation tree. Tables are distinguished from multidimensional datasets from which the statistics are extracted via an interactive tool. The data from 31 European countries have been analyzed and they concern the years 2004-2016. The analyzed period was selected according to the day of joining the European Union by the Czech Republic and by Poland (2004) and availability of data (2016). These countries were selected due to nationalities of the authors and close economic relations between them [9]. Additionally, countries with a similar average of passengers in the investigated dates were chosen. The number of carried passengers is presented in Table 1 and in Figure 1.

One of the goals of this analysis is to find some indicators that can have an influence on the number of passengers in the future. The most used include

(i) the total number of distinct (unique) passengers that, in a given time interval, have travelled by plane,

(ii) mean passengers - the total number of passengers divided by the number of analyzed periods.

\section{Results and Discussion}

The group includes five member states of the European Union. Three of them-Austria, Belgium, and Finland-have very strong mutual correlations (Table 2). Poland is strongly correlated with Belgium and Finland. However, as for the Czech Republic, no correlation in regard to the rest of the group has been found. The discussed relationships are also visible in the graphs (Figure 4 ). This fact should be taken under analysis by economical experts.

3.1. Rate of Changes. In order to analyze the dynamics of air passenger transport, the rate of change was determined (Table 3). The rate of change is the speed at which a variable changes over a specific period of time. The rate of change is often used in regard to momentum, and it can be generally expressed as a ratio of a change in one variable relative to a change in another.

Year 2004 was chosen as the base. It is shown in the table that the number of passengers increased every year. The knowledge of the value of an increasing factor is very important especially in the forecast analysis $[10,11]$. Based on 


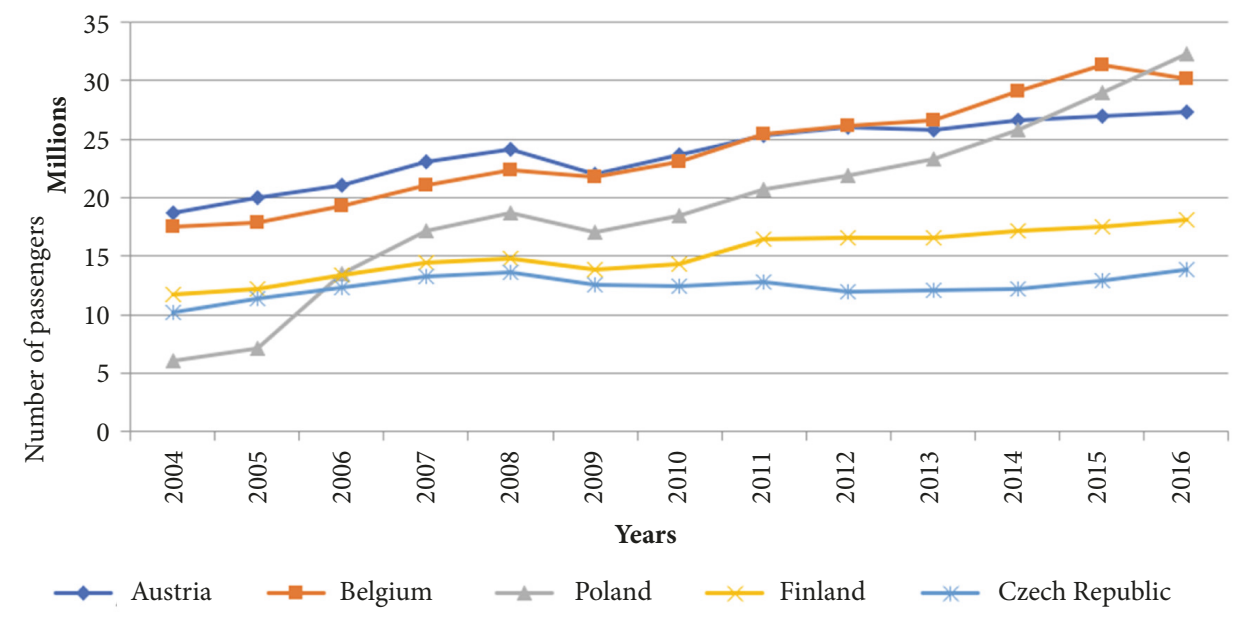

FIGURE 1: Number of passengers over the course of the analyzed years.

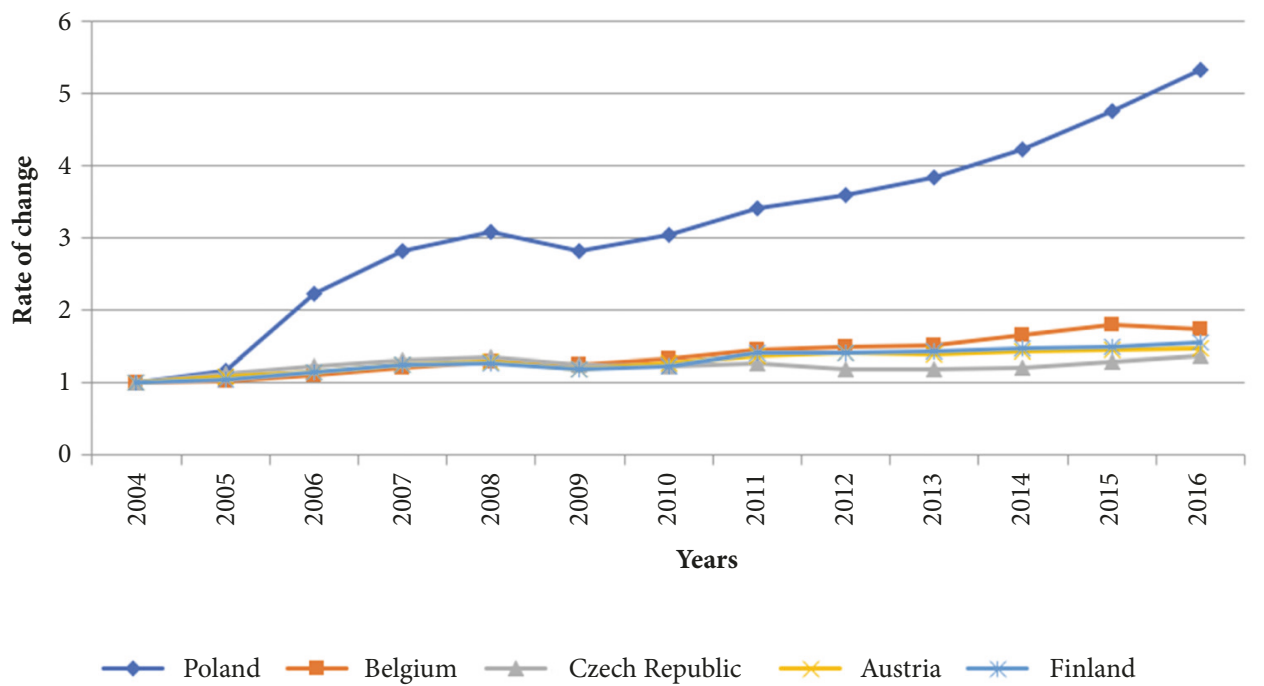

FigURE 2: Rate of change over the course of the analyzed years.

the presented trends, it can be predicted that in a few years a higher number of pilots and staff at the airport will be needed.

The rate of change is also presented in Figure 2. Based on the rate of changes shown, it can be concluded that the biggest growth is seen in Poland, while the smallest is in the Czech Republic. The authors of the paper do not intend to interpret results from the economical point of view but they are going to point out some possible causes of such a situation. One of them can be the usage of other means of transport in the analyzed countries [12]. The number of passengers who use the international railway is presented in Figure 3.

The number of passengers has been compared with the number of citizens and with the area of the Czech Republic and Poland. Results are presented in Table 4. It has been observed that, in 2004, the ratio of the passengers to citizens was 5 times smaller in Poland than in the Czech Republic. The number of tourists was also significantly smaller. One of the reasons for such a situation can be the level of net salary (the salary which is left after deducting tax and National Insurance contributions). The ratio of net salary in the Czech Republic and in Poland is presented in Figure 5.

The net salary can also have an influence on the number of passengers. The comparison between Poland and the Czech Republic is presented in Figure 4. The ratio between salaries in the Czech Republic and Poland is presented in Figure 5. It can be concluded that the discrepancy between both countries in net salaries is decreasing.

\section{Conclusions}

The knowledge about the number of passengers and the trends of changes will allow for predictions about the needs of air transport in the future. One of them is the number of pilots. One of the possibilities is to graduate from the academy in Dęblin. It takes around 5 years and a number of flight hours. Another possibility is to acquire a flight license on 


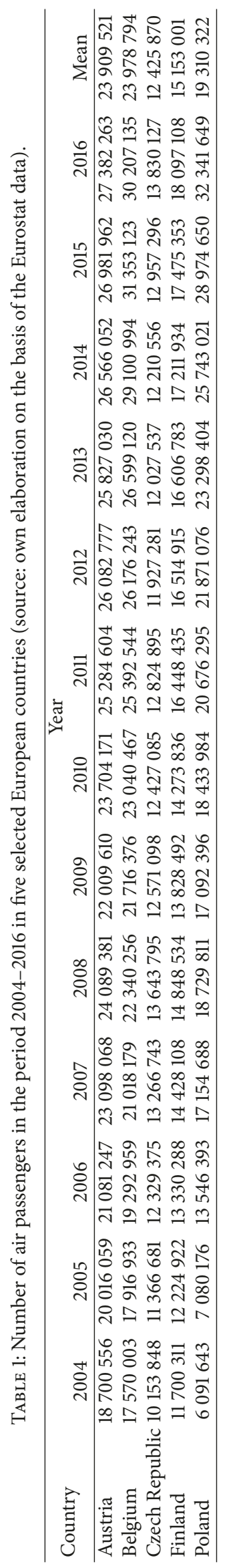




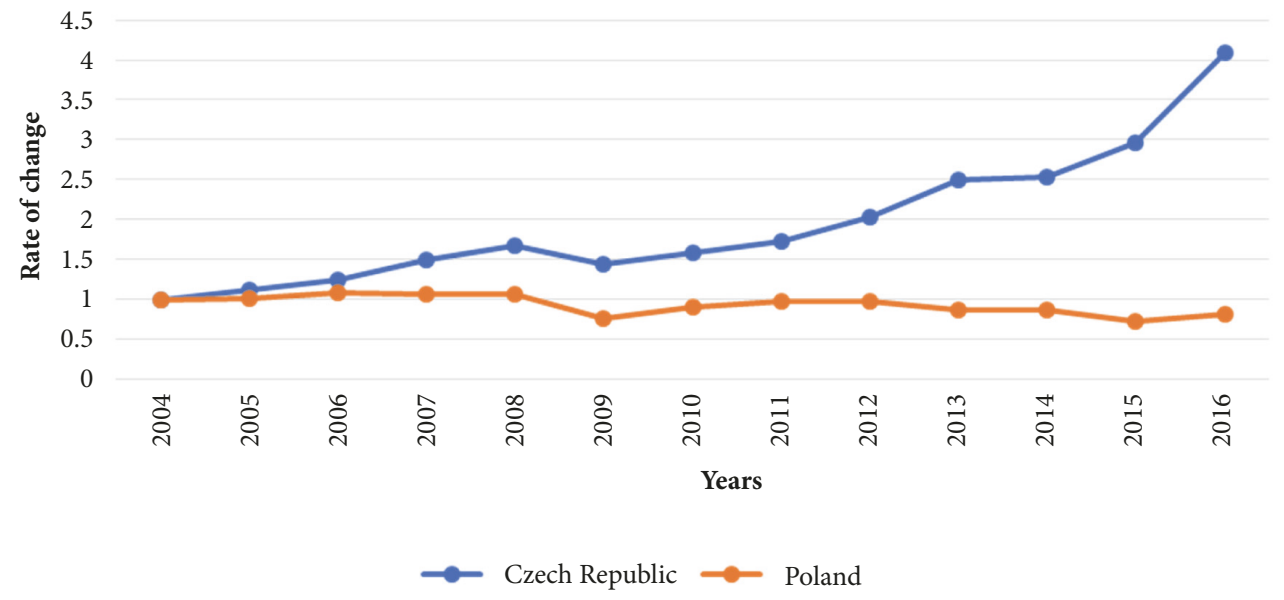

Figure 3: Rate of change of number of the railway passengers in the Czech Republic and Poland.

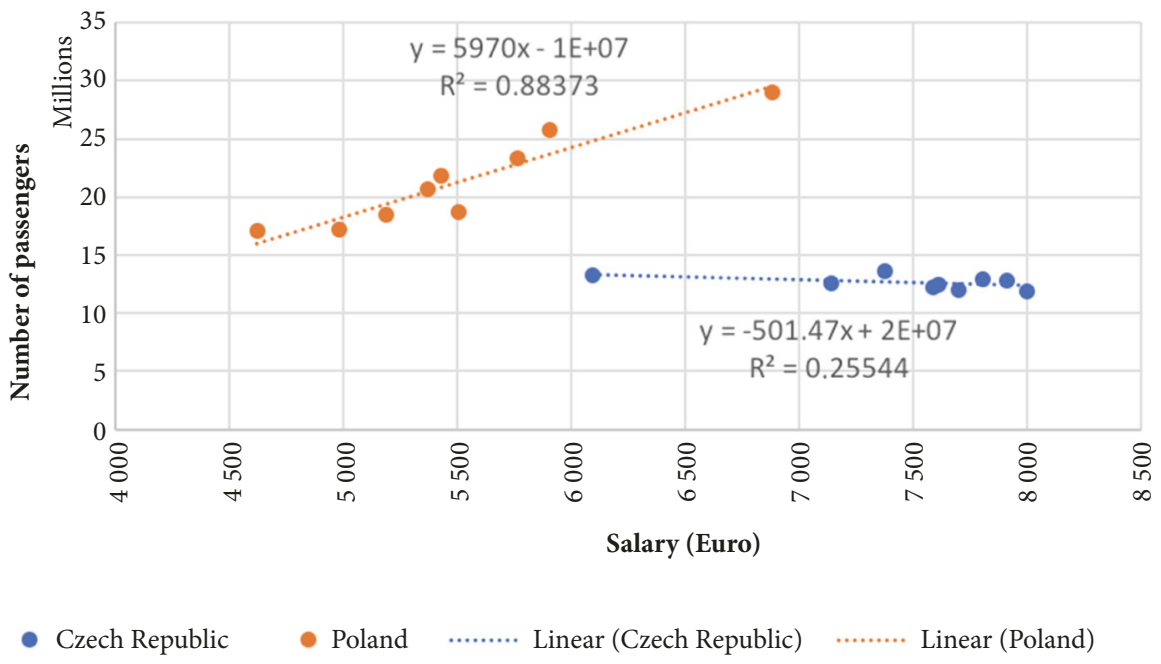

Figure 4: Salary over the years in the Czech Republic and Poland. Linear function is presented to guide the eyes.

TABLE 2: Matrix of dependencies between selected countries.

\begin{tabular}{|c|c|c|c|c|c|}
\hline Country & Austria & Belgium & Czech Republic & Finland & Poland \\
\hline Austria & 1 & 0.92 & -0.25 & 0.97 & 0.90 \\
\hline Belgium & 0.92 & 1 & -0.24 & 0.93 & 0.99 \\
\hline Czech Republic & -0.25 & -0.24 & 1 & -0.26 & -0.16 \\
\hline Finland & 0.97 & 0.93 & -0.26 & 1 & 0.91 \\
\hline Poland & 0.90 & 0.99 & -0.16 & 0.91 & 1 \\
\hline
\end{tabular}

their own and pay for every single hour. Even then, it takes at least 2 years. In the Czech Republic, there is a possibility to study at the Faculty of Transportation Sciences at the Czech Technical University in Prague. It is a bachelor study program and it takes 3 years. Another possibility is to study at the University of Defence in Brno; however it is dedicated only for military pilots. Nevertheless, some continue their career as airline pilots after completing military service.
Other requirements that may occur in relation to the expected growth of demand for air transport are demands for a trained crew, aircraft maintenance workers, and other related professions. These are such specific professions that a sufficient number of "free" workers of such professions cannot be found on the labour market. Therefore, it is necessary to be aware of this need and start planning the education and training well in advance.

The increase of requirements of air travel brings along not only increased requirements of a trained personnel, but also technical equipment, i.e., the number of aircrafts. With regard to the fact that ordering and production of an aeroplane are very costly and time-consuming, it is another reason for conducting statistical research, market mapping, and observing trends of market development.

In transport analysis, the term "reliability" usually means punctuality [13-16] but for the purpose of this analysis it has been redefined. Based on the number of passages, the number of passengers expected in the near future can be predicted. 
TABLE 3: Rate of change in the analyzed countries in 2004-2016.

\begin{tabular}{|c|c|c|c|c|c|c|c|c|c|c|c|c|c|c|}
\hline \multirow{2}{*}{ Country } & \multicolumn{14}{|c|}{ Year } \\
\hline & 2004 & 2005 & 2006 & 2007 & 2008 & 2009 & 2010 & 2011 & 2012 & 2013 & 2014 & 2015 & 2016 & Average rate of change $\%$ \\
\hline Austria & 1.000 & 1.070 & 1.127 & 1.235 & 1.288 & 1.177 & 1.268 & 1.352 & 1.395 & 1.381 & 1.421 & 1.443 & 1.464 & 3.40 \\
\hline Belgium & 1.000 & 1.020 & 1.098 & 1.196 & 1.271 & 1.236 & 1.311 & 1.445 & 1.490 & 1.514 & 1.656 & 1.784 & 1.719 & 5.40 \\
\hline Czech Republic & 1.000 & 1.119 & 1.214 & 1.307 & 1.344 & 1.238 & 1.224 & 1.263 & 1.175 & 1.185 & 1.203 & 1.276 & 1.362 & 2.60 \\
\hline Finland & 1.000 & 1.045 & 1.139 & 1.233 & 1.269 & 1.182 & 1.220 & 1.406 & 1.411 & 1.419 & 1.471 & 1.494 & 1.547 & 3.70 \\
\hline Poland & 1.000 & 1.162 & 2.224 & 2.816 & 3.075 & 2.806 & 3.026 & 3.394 & 3.590 & 3.825 & 4.226 & 4.756 & 5.309 & 14.9 \\
\hline
\end{tabular}

TABLE 4: Number of passengers as related to salary. The analysis is based on the Eurostat data.

\begin{tabular}{|c|c|c|c|c|c|c|c|c|c|c|c|c|c|}
\hline \multirow[b]{2}{*}{2004} & \multicolumn{13}{|c|}{ Poland } \\
\hline & 2004 & 2005 & 2006 & 2007 & 2008 & 2009 & 2010 & 2011 & 2012 & 2013 & 2014 & 2015 & 2016 \\
\hline Number of passengers (millions) & 6 & 7 & 13 & 17 & 19 & 17 & 18 & 21 & 22 & 23 & 26 & 29 & 32 \\
\hline Area $\left(\mathrm{km}^{2}\right)$ & \multicolumn{13}{|c|}{312679} \\
\hline Number of citizens (millions) & \multicolumn{13}{|c|}{38} \\
\hline Number of tourists (millions) & 9 & 10 & 10 & 11 & 10 & 10 & 10 & 11 & 12 & 12 & 13 & 14 & 15 \\
\hline Number of passengers per area & 19 & 23 & 43 & 55 & 59 & 55 & 59 & 66 & 70 & 75 & 82 & 93 & 103 \\
\hline \multirow[t]{2}{*}{ Number of passengers per citizens } & 0,2 & 0,2 & 0,4 & 0,5 & 0,5 & 0,5 & 0,5 & 0,5 & 0,6 & 0,6 & 0,7 & 0,8 & 0,9 \\
\hline & \multicolumn{13}{|c|}{ Czech Republic } \\
\hline Number of passengers (millions) & 10 & 11 & 12 & 13 & 14 & 13 & 12 & 13 & 12 & 12 & 12 & 13 & 14 \\
\hline Area $\left(\mathrm{km}^{2}\right)$ & \multicolumn{13}{|c|}{78866} \\
\hline Number of citizens (millions) & \multicolumn{13}{|c|}{10} \\
\hline Number of tourists (millions) & 19 & 19 & 20 & 21 & 20 & 18 & 18 & 19 & 22 & 22 & 22 & 23 & 24 \\
\hline Number of passengers per area & 129 & 144 & 156 & 168 & 173 & 159 & 157 & 163 & 151 & 153 & 155 & 164 & 175 \\
\hline Number of passengers per citizens & 1,0 & 1,1 & 1,2 & 1,3 & 1,3 & 1,2 & 1,1 & 1,2 & 1,1 & 1,1 & 1,1 & 1,2 & 1,3 \\
\hline
\end{tabular}

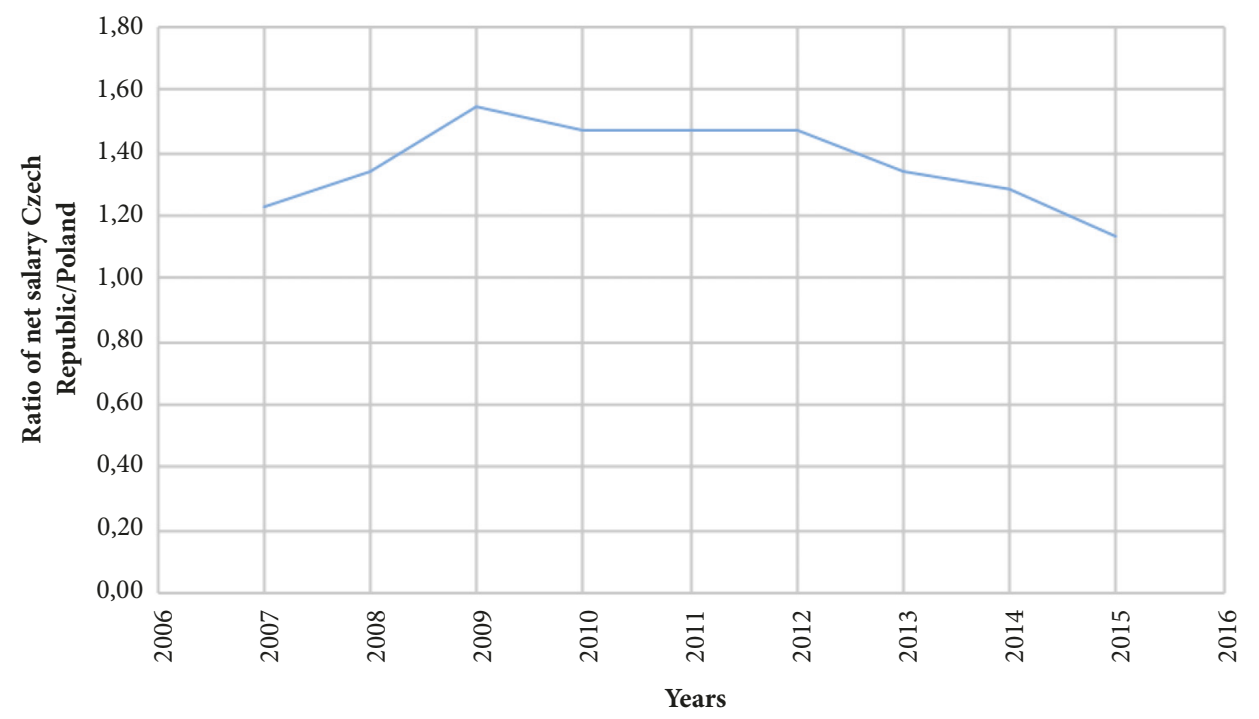

Figure 5: Ratio of net salary in the Czech Republic and in Poland.

This article was mainly focused on two countries, both belonging to the EU and being neighbouring countries. Nevertheless, the performed analysis showed different results.

If the rate of change remains on the current level within 5 years, it can be expected that the number of passengers in Poland will increase up to 44 million. This means that not only a larger crew, but also more aircraft will be necessary. The forecast of air traffic presented by the Civil Aviation Office in 2017 shows that, in 2035, over 94 million passengers will be transported at the Polish airports, almost three times more than in 2016. According to the experts from the Civil Aviation Office, Poland makes up for the distance to the Western European markets which is why further growth is expected in subsequent years [17]. 
On the other hand, increasing expectations are not so high in the Czech Republic. This is the consequence of the transport policy, published by the Ministry of Transport in June 2013 which suggests shifting 50\% of medium and long-distance freight transport from the road to the rail and waterborne transport and, in the case of passenger transport, significantly raising the proportion of rail transport (also moving away from air transport in distances under $1,000 \mathrm{~km}$, making room to air transport for long-distance flights [17].

\section{Data Availability}

All used data are from publicly available and quoted sources.

\section{Conflicts of Interest}

The authors declare that there are no conflicts of interest concerning the publication of this paper.

\section{Acknowledgments}

The work presented in this paper was supported within the project [Project code: DZRO 217] by the Ministry of Defence of the Czech Republic. The work presented in this paper was also supported by MŠMT ČR, research project no. SV17FVL_K106-BEN: "Identification and security of places with high population movement".

\section{References}

[1] V. Neumann, "Possibilities of vehicle movement evaluation," in Transport Means 2015, pp. 177-180, Kaunas, Lithuania: Kaunas University of Technology, 2015.

[2] P. Giudici, Applied Data Mining Statistical Methods for Business and Industry, John Wiley \& Sons, Chichester, UK, 2003.

[3] M. A. Anna, Wstęp do statystyki. Metody opisu statystycznego, Wydawnictwo Uniwersytetu Warszawskiego, Warszawa, 2007.

[4] J.-R. Barra, Matematyczne podstawy statystyki, Wydawnictwo Naukowe PWN, Warszawa, 1982.

[5] OpenStax, Introductory Business Statistics, OpenStax OpenStax Business Statistics OpenStax Business Statistics, 2018.

[6] J. Cohen, P. Cohen, S. G. West, and L. S. Aiken, Applied Multiple Regression/Correlation Analysis for the Behavioral Sciences, Taylor \& Francis, 2013.

[7] L. Socha, Linearization Methods for Stochastic Dynamic Systems, vol. 730 of Lectures Notes in Physics, Springer-Verlag Berlin Heidelberg, 2008.

[8] Eurostat, European Union, http://ec.europa.eu/eurostat/.

[9] A. Orzelska, "Współpraca regionalna w Europie ŚrodkowoWschodniej w polskiej polityce zagranicznej," Myśl Ekonomiczna i Polityczna, vol. 2, pp. 238-262, 2015.

[10] G. E. P. Box and G. M. Jenkins, Jenkins, Time series analysis, forecasting and control, Prentice Hall, NY, USA, 1976.

[11] P. Deuflhard and A. Hohmann, Numerical analysis in modern scientific computing, vol. 43 of Texts in Applied Mathematics, Springer-Verlag, New York, Second edition, 2003.

[12] Š. Hošková-Mayerová and O. Becherová, "Risk of probable incidents during railways transport," Problemy Transportu I Logistyki, vol. 33, pp. 15-23, 2016.
[13] T. Najbrt and K. Hasilová, "Impact of the financial crisis of 2008 on furniture industry in the Czech Republic and development of tangible fixed assets in 2005- 2012 and its possible renewal," Acta Universitatis Agriculturae et Silviculturae Mendelianae Brunensis, vol. 64, no. 3, pp. 1045-1052, 2016.

[14] N. Bhouri, M. Aron, and G. Scemama, "Travel time reliability with and without the dynamic use of hard shoulder: Field assessment from a French motorway," Journal of Traffic and Transportation Engineering (English Edition), vol. 3, no. 6, pp. 520-530, 2016.

[15] C. Carrion and D. Levinson, "Value of travel time reliability: a review of current evidence," Transportation Research Part A: Policy and Practice, vol. 46, no. 4, pp. 720-741, 2012.

[16] F. Maturo, "On an extension of the dubins conditional probability axiomatic to coherent probability of fuzzy events," Italian Journal of Pure and Applied Mathematics, vol. 2018, no. 39, pp. 810-821, 2018.

[17] Civil Aviation Office, http://www.ulc.gov.pl/pl/publikacje/ wiadomosci/4284-ulc-nowa-prognoza-ruchu-lotniczego-dobreperspektywy-rozwoju-dla-polskich-lotnisk. 


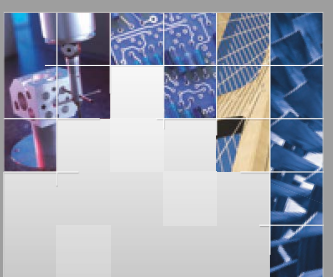

\section{Enfincering}
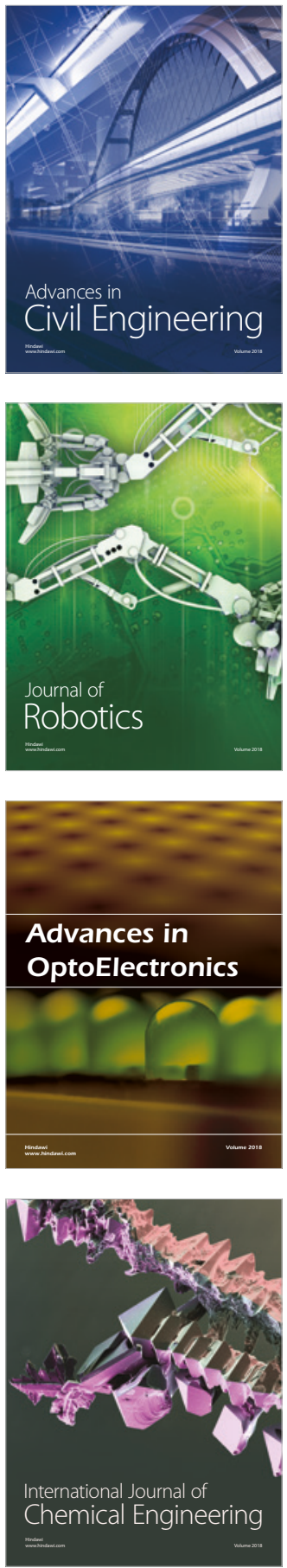

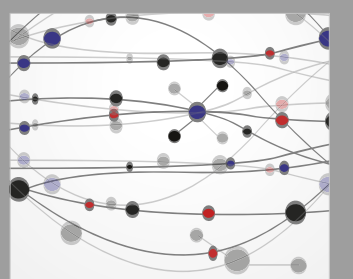

\section{Rotating \\ Machinery}

The Scientific World Journal

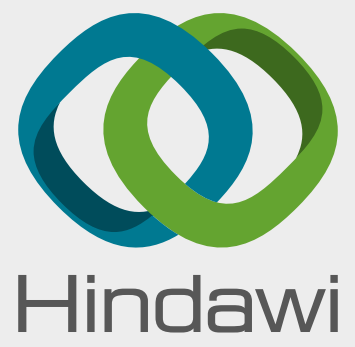

Submit your manuscripts at

www.hindawi.com
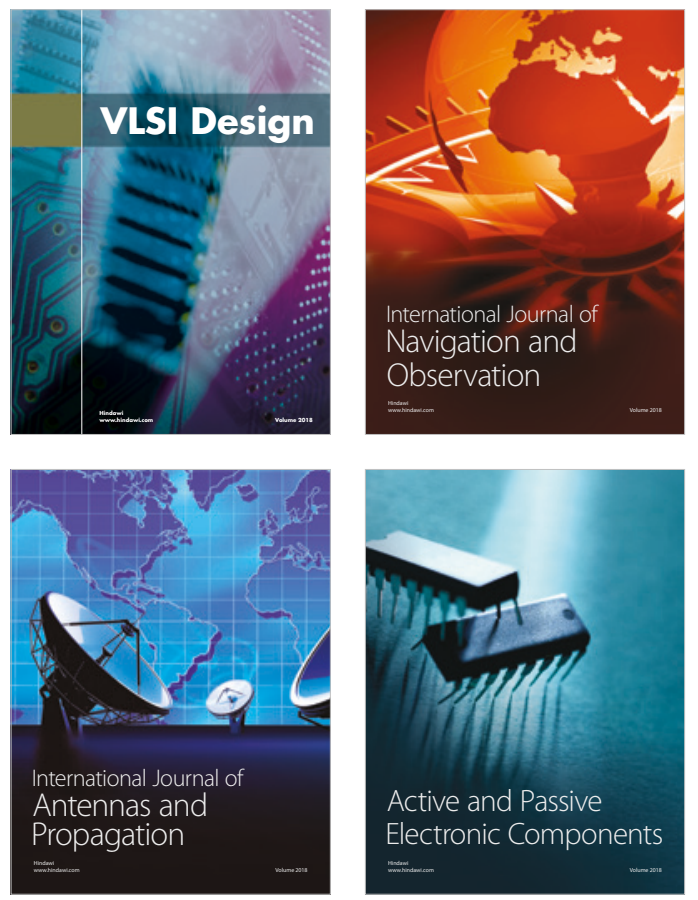
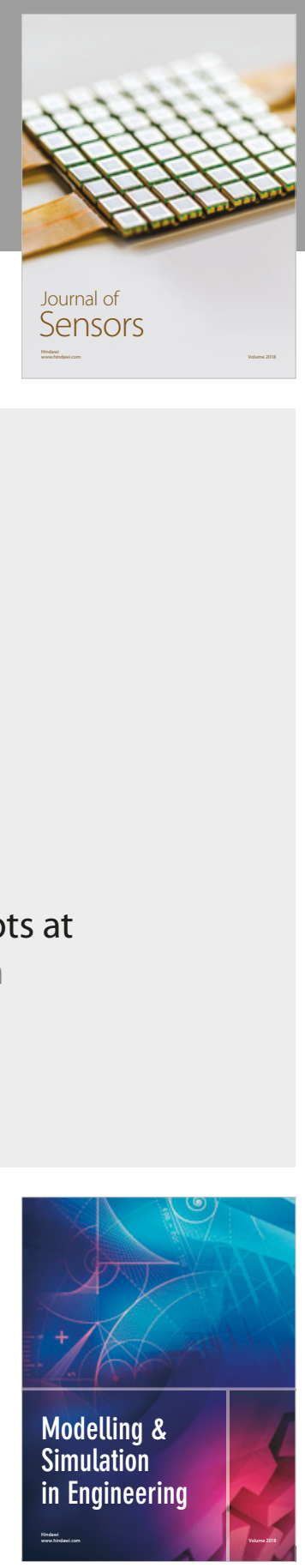

\section{Advances \\ Multimedia}
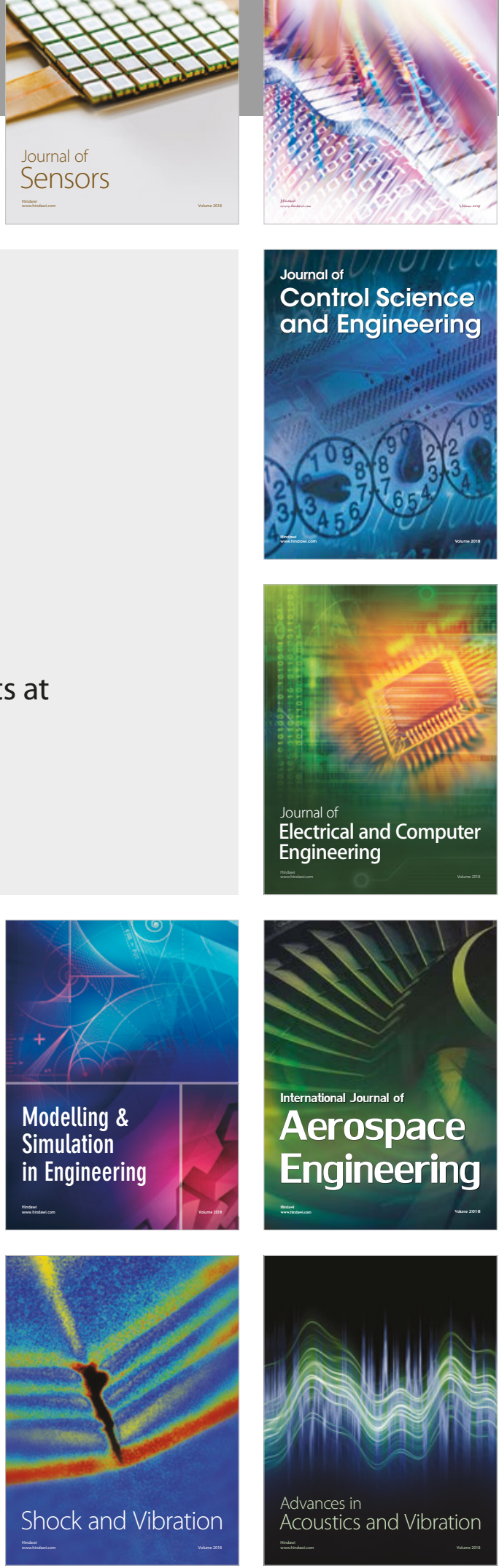